Short Communication

\title{
Genotype Detection and Sero-prevalence of Bovine Leukemia Virus along with Associated Risk Factors in Exotic and Local Breeds of Cattle in and Around Lahore, Punjab
}

\author{
Rao Muhammad Ramiz ${ }^{1}$, Arfan Ahmad ${ }^{2 *}$, Aamir Ghafoor ${ }^{2}$, Muhammad Avais $^{3}$, \\ Qurat-ul-Ain ${ }^{1}$ and Muhammad Zahid Iqbal ${ }^{3}$ \\ ${ }^{1}$ Department of Microbiology, University of Veterinary and Animal Sciences, Lahore \\ ${ }^{2}$ University Diagnostic Laboratory, University of Veterinary and Animal Sciences, \\ Lahore \\ ${ }^{3}$ Department of Clinical Medicine and Surgery, University of Veterinary and Animal \\ Sciences, Lahore
}

\begin{abstract}
A B S T R A C T
Bovine leukemia virus (BLV) is the cause of enzootic bovine leukosis and has worldwide distribution. This is study reports presence and genetic diversity of BLV in cattle of two districts of Punjab, Pakistan. Blood samples $(n=400)$ taken from local $(n=200)$ and exotic $(n=200)$ breeds of cattle were processed for complete blood count. Based on lymphocyte counts, samples were divided into two groups (A, lymphocytosis, B, normal lymphocytes) and tested through ELISA and nested PCR for serological investigations and molecular characterization respectively. In this study, animals of group A (32.5\%) showed significantly greater seropositivity $(\mathrm{P}<0.05)$ against $\mathrm{BLV}$ than group $\mathrm{B}(16 \%)$. Furthermore, exotic breeds of cattle showed significantly greater seropositivity $(18.75 \%)$ compared to the local breeds of cattle $(5.5 \%)$. Nested PCR on each of the $10 \%$ seropositive and negative samples confirmed BLV infection in three seropositive exotic animals $(30 \%)$. Phylogenetic analysis revealed the circulation of BLV genotype 1 in exotic breeds of cattle. Evaluation of various risk factors analysis demonstrated the strong positive association of BLV with age, herd size, parity, breeding (AI, Bull) and country of import. The animals found positive were imported from US, therefore there is a need to conduct a national epidemiological study on BLV to find out its true picture.
\end{abstract}

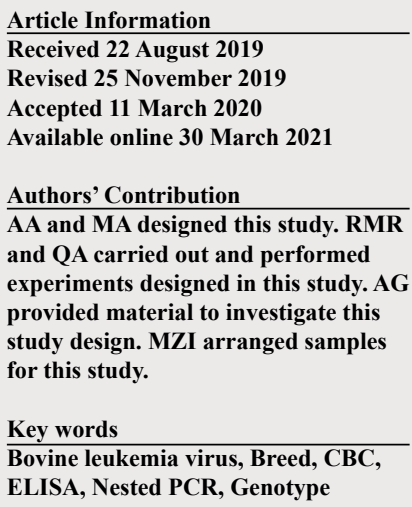

$\mathrm{B}_{\mathrm{r}}$ ovine leukemia virus (BLV) of the family Retroviridae has worldwide distribution and is the cause of enzootic bovine leukosis, a neoplastic disease of lymphatic tissue in cattle (Mousavi et al., 2014). Most of the infected animals develop a leukemic stage and approximately $30 \%$ progress to persistent lymphocytosis because of polyclonal expansion of B-cells. This form serves as a reservoir of infection in herds and is deemed as a benign stage, whereas $0.1-10 \%$ of the infected animals develop tumors, largely B-cell lymphosarcoma (Burny et al., 1988). The virus integrates itself into the genome of affected cells as a provirus and is found in the cellular fraction of various body fluids (Matsumura et al., 2011). Horizontal transmission occurs via transfer of biological fluids containing infected lymphocytes, such as blood, milk and saliva. Iatrogenic routes have also been reported to be involved in transfer of infection within a

\footnotetext{
Corresponding author: iffivet@uvas.edu.pk 0030-9923/2021/0003-1169 \$ 9.00/0

Copyright 2021 Zoological Society of Pakistan
}

herd. Vertical transmission takes place transplacentally and via feeding of colostrum from the infected dam (Polat et al., 2015). Western European countries have adopted an eradication program against BLV infection and now are declared a BLV free region. According to recent epidemiological studies the global distribution of BLV infection in many countries is as low as 5\% in Cambodia and Taiwan (Wang, 1991) and as high as 83.9\% in the USA (Bartlett et al., 2014). BLV envelope gene encodes two disulfide-linked glycoproteins, gp30 and gp5. Glycoprotein 51 is essential for virus life cycle and plays a critical role in virus-host interaction because it is mainly involved in infectivity (Callebaut et al., 1993). According to recent research studies based on env gene analysis, BLV has been classified into 10 genotypes (G1-G10) circulating in various geographical regions of the world with $94.5 \%$ $97.7 \%$ homology observed among the different isolates of BLV (Lee et al., 2016).

Despite being highly prevalent around the world, to date no study has ever been conducted to determine the distribution of infection in Pakistan. Therefore, this study 
was planned aiming to investigate the status of BLV in Lahore and Kasur districts of Punjab using ELISA and Nested-PCR.

\section{Materials and methods}

In this study exotic (Holstein Friesian (HF) and native Sahiwal, non-descriptive) breeds of cattle housed in two districts of Punjab, Pakistan: Lahore and Kasur were selected for this study on the basis of the presence of all breeds of cattle. A total of 400 blood and serum samples were collected aseptically from exotic $(n=200)$ and native $(n=200)$ breeds of cattle. Using whole blood, complete blood counts were completed using the automatic junior jet vet hematological analyzer (Abacus Junior Vet). Based on lymphocyte counts, samples were divided into two groups A; lymphocytosis, B; normal lymphocytes and serum tested for seropositivity against BLV and molecular characterization. Seroconversion against BLV was assessed by indirect ELISA (IDEXX, USA) as per manufacturer's instructions.

\section{Table I. BLV primer.}

\begin{tabular}{lll}
\hline Oligo & Sequence & Position \\
\hline BLV-env-1 & TCT-GTG-CCA-AGT-CTC-CCA-GAT-A & 5032-5053 \\
BLV-env-2 & AAC-AAC-AAC-CTC-TGG-GAA-GGG & $5629-5608$ \\
BLV-env-3 & CCC-ACA-AGG-GCG-GCG-CCG-GTT-T & $5099-5121$ \\
BLV-env-4 & GCG-AGG-CCG-GGT-CCA-GAG-CTG-G & 5542-5521 \\
\hline
\end{tabular}

Nested PCR targeting the env gene was performed on $10 \%$ of each of the ELISA positive and negative samples as previously described (Fechner et al., 1997). PCR products were analyzed using gel electrophoresis. The primers used are listed in Table I. Briefly, primers BLV-env-1/BLVenv-2 were used in the first round of PCR resulting in the amplification of a $598 \mathrm{bp}$ product. In the second round of test, $2 \mu$ of the first round PCR amplicon was transferred to a new tube containing fresh master mix and primers BLVenv-3/BLV-env-4. The presence of a $444 \mathrm{bp}$ fragment was considered positive. After Nested PCR, the PCR product was sequenced and aligned using Clustal $\mathrm{W}$ in BioEdit v. 5.0.6. The phylogenetic tree was constructed using MEGA 6.0 by applying neighbor joining method. During sample collection data regarding risk factors including age, herd size, parity, breeding and country of import was recorded on a predesigned performa.

\section{Results and discussion}

Of the 400 samples processed through ELISA, irrespective of breed and lymphocyte count, an overall $24.25 \%$ seropositivity was observed in the study area. In the present study, HL showed significantly greater $(\mathrm{P}<0.05)$ seroconversion against BLV (37.5\%) than Sahiwal (22\%) and nondescript breeds of cattle (0\%) (Table II). It was also observed that cattle of group A with higher lymphocyte counts showed more seropositivity $(32.5 \%)$ than group $\mathrm{B}$ with normal lymphocyte range (16\%) (Table III). The seroconversion against BLV within a breed on the basis of lymphocyte count showed a greater seropositivity percentage in the presence of a high lymphocyte count (Table II). Cattle housed in district Kasur showed significantly $(\mathrm{P}<0.05)$ more seropositivity $(43.5 \%)$ than in Lahore (5\%) (Table IV). In this study Nested PCR targeting the env gene was performed on $10 \%$ of the ELISA positive $(n=10)$ and negative $(n=30)$ samples each. Following the first round of PCR, the amplification of a $598 \mathrm{bp}$ fragment was considered positive (Supplementary Fig. 1) whereas after the second round of PCR, a 444bp product specific for BLV was observed (Supplementary Fig. 2). In our hands, only three samples originating from exotic (HL) cattle were found to be positive for BLV. None of the seronegative samples from any breed of cattle was positive using Nested PCR. Nucleotide sequences of the amplicons from this study were aligned using BioEdit with other parallel sequences of BLV representing genotypes 1-10 obtained from GeneBank. Phylogenetic analysis performed using MEGA 6.0 revealed the circulation of BLV genotype 1 (Fig. 3). The sequences of BLV from this study have close proximity to the Japanese and Thailand BLV strains.

In this study, the association of various risks factors with the occurrence of BLV was also analyzed. Age had a positive association $(\mathrm{P}<0.05)$ with the occurrence of $\mathrm{BLV}$. Seropositivity was greater in animals more than 2 years of age $(44.7 \%)$ compared to animals $<2$ years of age $(6.7 \%)$. Other risk factors including parity, herd size, breeding methods (AI, Bull) and country of import also showed a positive association with BLV infection.

Higher seropositivity was observed in cattle with parity $>2(36.3 \%)$ compared to those with parity $<2(12.4 \%)$.

Table II. Seropositivity (\%) against bovine leukemia virus through antibody capture ELISA on the basis of breeds of cattle.

\begin{tabular}{|c|c|c|c|c|c|c|}
\hline \multirow[t]{2}{*}{ Status } & \multicolumn{2}{|c|}{ Sahiwal } & \multicolumn{2}{|c|}{ Non-descript } & \multicolumn{2}{|c|}{ Holstein frisian } \\
\hline & $\begin{array}{l}\text { Lymphocyto- } \\
\text { sis }(n=50)\end{array}$ & $\begin{array}{l}\text { Normal lympho- } \\
\text { cytes }(n=50)\end{array}$ & $\begin{array}{l}\text { Lymphocyto- } \\
\text { sis }(n=50)\end{array}$ & $\begin{array}{l}\text { Normal lympho- } \\
\text { cytes }(n=50)\end{array}$ & $\begin{array}{l}\text { Lymphocytosis } \\
(\mathrm{n}=100)\end{array}$ & $\begin{array}{l}\text { Normal lympho- } \\
\text { cytes }(n=100)\end{array}$ \\
\hline Seropositive & $\begin{array}{l}15 \\
(30 \%)\end{array}$ & $\begin{array}{l}7 \\
(14 \%)\end{array}$ & $\begin{array}{l}0 \\
(0)\end{array}$ & $\begin{array}{l}0 \\
(0)\end{array}$ & $\begin{array}{l}50 \\
(50 \%)\end{array}$ & $\begin{array}{l}25 \\
(25 \%)\end{array}$ \\
\hline $\begin{array}{l}\text { Overall breed wise }(\%) \\
\text { Overall }(\%)\end{array}$ & $\begin{array}{l}22 \% \\
24.2 \%\end{array}$ & & 0 & & $37.5 \%$ & \\
\hline
\end{tabular}


Likewise, seropositivity of BLV infection among herd size of $>200$ and $<200$ was $37.1 \%$ and $8.9 \%$ respectively. According to the results of the present study, a higher seropositivity was observed in cattle imported from the USA compared to cattle imported from Australia. In addition, a greater seropositivity was found in artificially inseminated cows $(30.5 \%)$ compared to cows naturally service by a bull (12.7\%) (Table V).

Table III. Seropositivity (\%) against bovine leukemia virus through antibody capture ELISA on the basis of lymphocyte count.

\begin{tabular}{lll}
\hline Groups & Total samples tested & Seropositivity \\
\hline A (lymphocytosis) & 200 & $32.5(\%)$ \\
B (normal lymphocytes) & 200 & $16(\%)$ \\
\hline
\end{tabular}

Table IV. Distribution of BLV infection in targeted area.

\begin{tabular}{llll}
\hline District & No. of samples & Positive samples & Negative samples \\
\hline Lahore & 200 & $10(5 \%)$ & 190 \\
Kasur & 200 & $87(43.5 \%)$ & 113 \\
Total & 400 & $97(24.25 \%)$ & 303 \\
\hline
\end{tabular}

Table V. Association of various risk factors with occurrence of BLV.

\begin{tabular}{lllll}
\hline Variables & Categories & $\begin{array}{l}\text { Positive/ } \\
\text { Negative }\end{array}$ & $\begin{array}{l}\text { Prevalence } \\
(\%)\end{array}$ & p-Value \\
\hline Age & Less than 2 & $09 / 126$ & 6.7 & 0.001 \\
& More than 2 & $92 / 173$ & 44.7 & \\
Parity & Less than 2 & $23 / 162$ & 12.4 & 0.001 \\
& More than 2 & $78 / 137$ & 36.3 & \\
Herd size & Less than 200 & $15 / 153$ & 8.9 & 0.001 \\
& More than 200 & $86 / 146$ & 37.1 & \\
Breeding & AI & $86 / 196$ & 30.5 & 0.002 \\
\multirow{4}{*}{ Country of } & Bull & $15 / 103$ & 12.7 & \\
import & America & $74 / 0$ & 100 & 0.001 \\
\hline \multicolumn{6}{l}{} & Australia & $0 / 126$ & 0 & \\
\hline
\end{tabular}

In this study, an overall $24.25 \%$ seropositivity against BLV was observed in the study area. This seropositivity finding is in close agreement with the prevalence (24.6\%) reported in Iran (Mousavi et al., 2014). However, our study results are not in concordance with the findings of research conducted in Turkey (17\%) and Taiwan (5\%) where a lower prevalence was observed (Wang, 1991). Our study results also showed disagreement with the study conducted in Thailand (32.5\%) and Korea (35\%) (Lee et al., 2016). The possible reason for these discrepancies could be attributed to the housing of different breeds of cattle imported from other countries and the variety of animal rearing practices. In our study, more BLV positivity was observed in exotic than in native breeds. It can be ascribed to prior infection of BLV in these exotic cattle in their native country where BLV has its presence and BLV infection could have been carried in to the study area on importation. Non-descript breed of cattle showed $0 \%$ positivity as compared to Sahiwal and HL breeds. It is possible that the non-descript breed cattle had not been exposed to BLV via any mode of transmission as compared to other breeds which were likely to get infection from the introduction of an infected animal to the herd. We also found that more BLV positivity was noted in the district of Kasur as compared to Lahore. This may be related to sheltering of more exotic cattle and larger herd sizes in district Kasur, as herd size has been reported as a potential risk factor for BLV (Sun et al., 2015). More seropositivity was observed in animals having elevated lymphocyte counts compared to animals with a normal range of lymphocytes. It might be possible that most of the seropositive animals screened in this study had progressed to the persistent lymphocytosis (PL) stage.

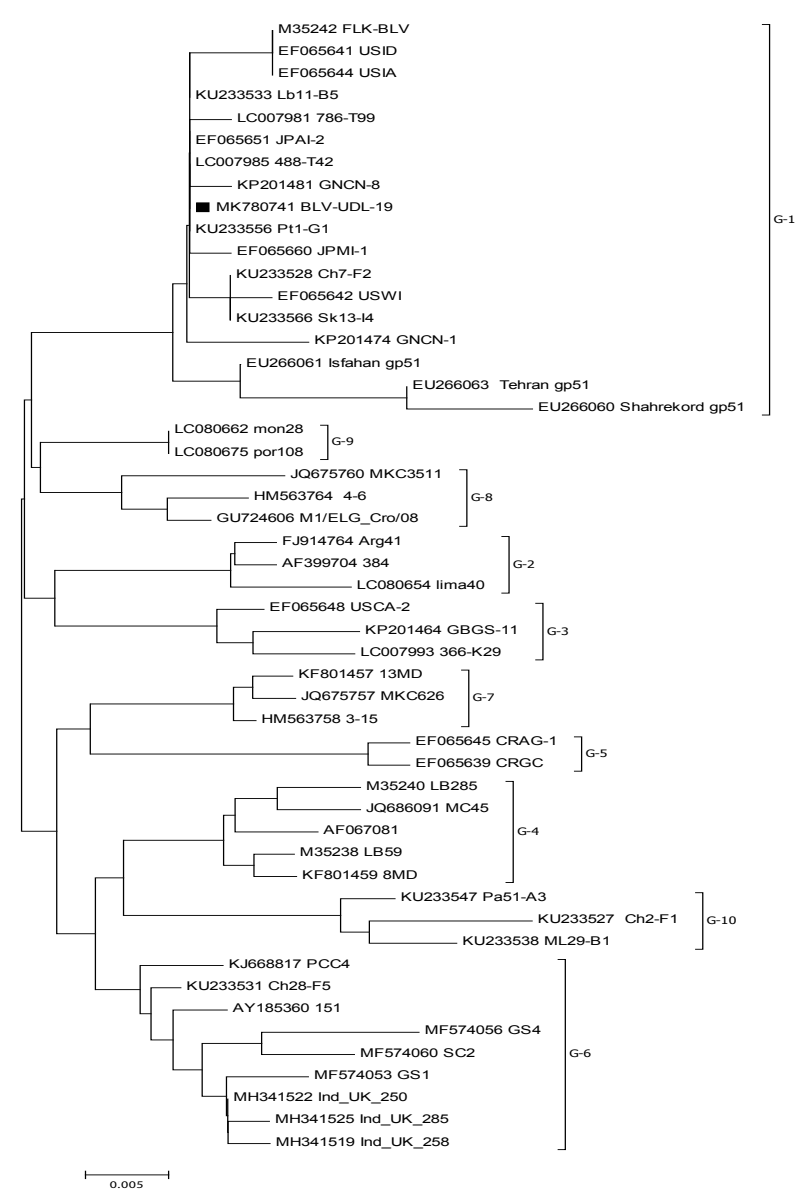

Fig. 1. Phylogenetic tree based on partial $E N V$ gene.

Out of the $10 \%$ seropositive samples $(n=10)$ evaluated, PCR confirmed three samples originating from exotic cattle were positive for BLV. The possible reason for the discrepancy between antibody capture ELISA and 
PCR may be that BLV genomic DNA was not present in circulating lymphocytes as has been reported in another study (Murtaugh et al., 1991). In our hands none of the seronegative samples $(n=30)$ were positive by PCR.

After sequencing, phylogenetic analysis revealed the circulation of BLV genotype 1 in the study area. BLV genotype 1 has been reported in many areas of the world including the US, Asia, Australia and South America (Gautam et al., 2018). Genotype 1 when analyzed by MEGA 6.0 was shown to have a close proximity to the Thailand and Japanese isolates and to a certain extent with US isolates. Results of this study are in agreement with those conducted in Japan (Matsumura et al., 2011) in which the author theorized the possible entry of BLV infection might be from US imported animals.

In this study the association between BLV infection and various variables was also evaluated. Our findings showed that the infection rate of BLV increased with age, herd size and calving. A higher seropositivity was observed in older animals, $>2$ years of age. The longer the lifespan of an animal, the greater the chances of exposure and contact between BLV-infected and non-infected animals. This can be attributed to the higher seroprevalence of BLV in aged animals. The present study demonstrated more positivity of BLV in herds harboring more than 200 animals. Close physical contact among animals in densely populated herds could account for the greater rate of infection. Similar results have been reported by other studies as well (Sun et al., 2015). Regarding parity, an increased rate of BLV infection was observed with parity. Age and parity are linked and it is hard to separate both. The probability of contact transmission increases with age and parity, therefore seropositivity gets higher in multiparous animals (Mousavi et al., 2014). This study found an association between breeding method and BLV seropositivity. A greater seropositivity was observed in animals bred with AI compared to natural service. On farms, it is a regular practice to use a common glove for AI of multiple animals during which the blood contaminated glove may transmit BLVinfected lymphocytes among individual animals within the herd (Kohara et al., 2006). The present study proved significant association between the country of import and BLV infection. Dairy cows imported from the US showed more positivity of BLV compared to those imported from Australia. It is possible that cows had carried infection from the US when imported into Pakistan since the US has a high prevalence of BLV (Bartlett et al., 2014). Since this study was conducted on limited number of animals, testing on a large scale may change our assumption.

\section{Conclusion}

This study confirmed the presence of genotype 1 of BLV in exotic breed of cattle in Punjab.
Acknowledgement

We are thankful to Dr. Jacek Kuzmak from the National Veterinary Research Institute, Poland for providing us positive control of BLV to optimize Nested PCR.

\section{Supplementary material}

There is supplementary material associated with this article. Access the material online at: https://dx.doi. org/10.17582/journal.pjz/20190822070849

\section{Statement of conflict of interest}

The authors have declared no conflict of interest.

\section{References}

Bartlett, P.C., Sordillo, L.M., Byrem, T.M., Norby, B., Grooms, D.L., Swenson, C.L., Zalucha, J. and Erskine, R.J., 2014. J. Am. vet. med. Assoc., 244: 914-922. https://doi.org/10.2460/javma.244.8.914

Burny, A., Cleuter, Y., Kettmann, R., Mammerickx, M., Marbaix, G., Willems, L. and Thomas, R., 1988. Virus Infect. Dev. Nerv. Syst. Springer, 1988: 37-56.

Callebaut, I., Voneche, V., Mager, A., Merza, M., Burny, A. and Portetelle, D., 1993. J. Virol., 67: 5321-5327. https://doi.org/10.1128/JVI.67.9.5321-5327.1993

Fechner, H., Blankenstein, P., Looman, A.C., Elwert, J., Geue, L., Albrecht, C., Kurg, A., Beier, D., Marquardt, O. and Ebner, D., 1997. Virology, 237: 261-269. https://doi.org/10.1006/viro.1997.8784

Gautam, S., Mishra, N., Kalaiyarasu, S., Jhade, S.K. and Sood, R., 2018. Transbound. Emerg. Dis., 65: 1968-1978. https://doi.org/10.1111/tbed.12979

Kohara, J., Konnai, S. and Onuma, M., 2006. Japanese J. Vet. Res., 54: 25-30.

Lee, E., Kim, E.J., Ratthanophart, J., Vitoonpong, R., Kim, B.H, Cho, I.S, Song, J.Y., Lee, K.K. and Shin, Y.K., 2016. Infect. Genet. Evol., 41: 245-254.

Matsumura, K., Inoue, E., Osawa, Y. and Okazaki, K., 2011. Virus Res., 155: 343-348. https://doi. org/10.1016/j.virusres.2010.11.005

Mousavi, S., Haghparast, A., Mohammadi, G. and Tabatabaeizadeh, S.E., 2014. Faculty of Veterinary Medicine, Urmia University, Urmia, Iran, 5: 135.

Murtaugh, M., Lin, G., Haggard, D., Weber, A. and Meiske, J., 1991. J. Virol. Methods, 33: 73-85. https://doi.org/10.1016/0166-0934(91)90009-O

Polat, M., Ohno, A., Takeshima, S.N., Kim, J., Kikuya, M., Matsumoto, Y., Mingala, C.N., Onuma, M. and Aida, Y., 2015. Arch. Virol., 160: 285-296. https:// doi.org/10.1007/s00705-014-2280-3

Sun, W.W., Lv, W.F., Q.F., Wang, C.F., Shan, X.F. and Qian, A.D., 2015. Biomed. Res. Int., Article ID $315173 \mathrm{https}: / /$ doi.org/10.1155/2015/315173

Wang, C.T., 1991. J. vet. med. Sci., 53: 395-398. https:// doi.org/10.1292/jvms.53.395 